
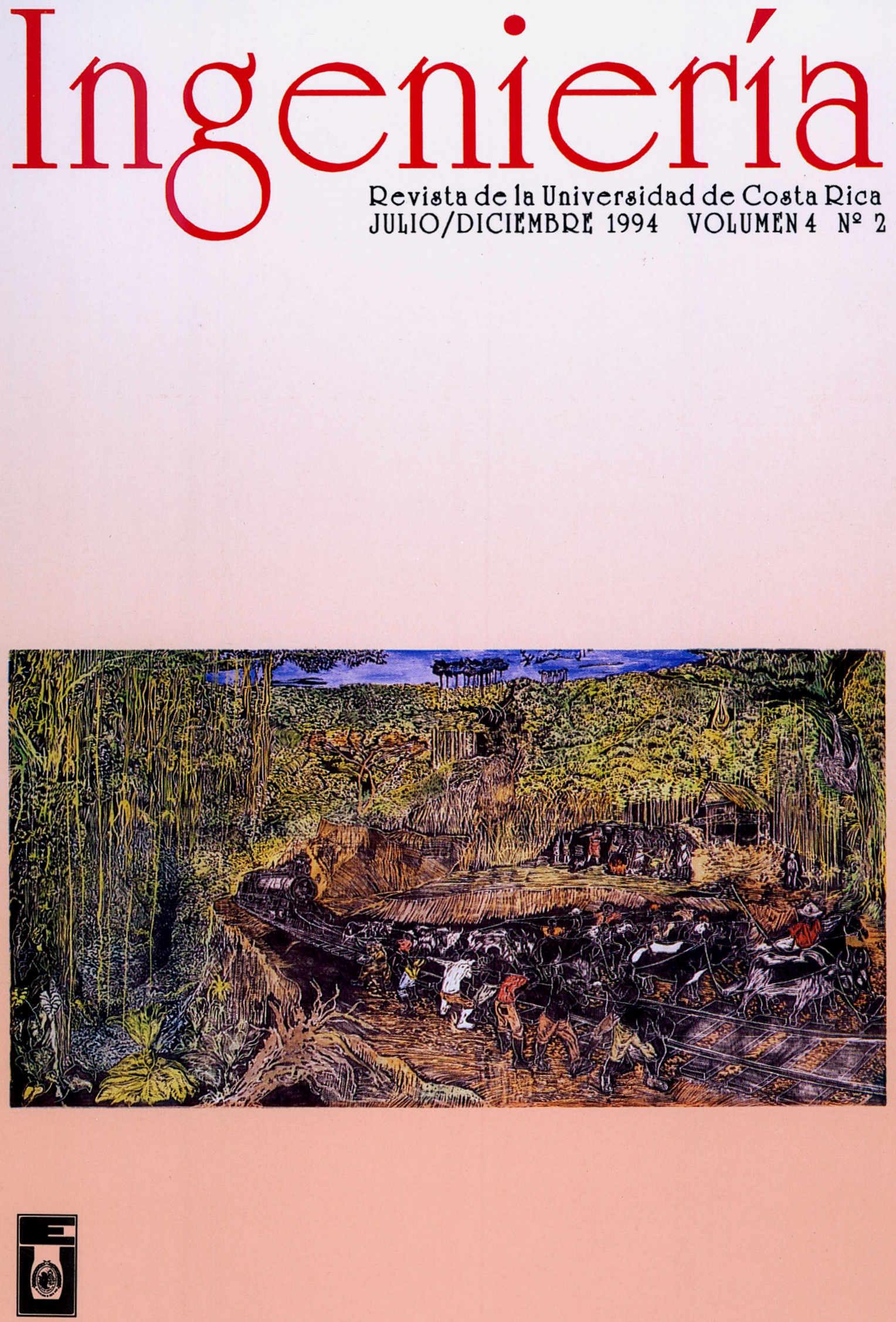


\title{
DAMAGE POTENTIAL OF EARTHQUAKE GROUND MOTIONS RECORDED IN SOUTHERN CENTRAL AMERICA
}

\author{
Guillermo Santana* \\ Amador Terán *
}

\begin{abstract}
RESUMEN
Un total de 18 diferentes componentes de movimientos sísmicos registrados en América Central fueron seleccionados para hacer una evaluación de su potencial de daño. Se puso énfasis en los sismos registrados en la reciente actividad sísmica de Costa Rica. Con el propósito de comparación fueron incluidos en el estudio cinco registros obtenidos en diferentes partes del mundo. Como medio para identificar el potencial de daño de los registros, la energía de entrada así como el espectro de energía plástica histerética fueron calculados para diferentes niveles de ductibilidad de los desplazamientos y un coeficiente de amortiguamiento viscoso $\sim=0.05$. El efecto de la duración del movimiento sísmico fue estudiado introduciendo el parámetro no-dimensional y y el blanco de ductibilidad $\mu \mathrm{T}$ AR. El parámetro y es una función del máximo desplazamiento y de la demanda de disipación de energía plástica histerética. Los cálculos fueron realizados para sistemas de un grado de libertad con comportamiento elastoplástico histerético. Otras magnitudes de respuesta fueron consideradas fueron la demanda de ductibilidad basada en resistencia constante y la demanda de resistencia basada en la ductibilidad constante. Los resultados son contrastados con las normas de diseño sísmico vigentes en la región tal y como se presentan en los códigos de construcción más recientes.
\end{abstract}

\section{SUMMARY}

A total of 18 different components of earthquake ground motion recorded in Central America were selected to conduct an evaluation oftheir damage potential. Emphasis was placed in ground motions recorded during recent seismic activity in Costa Rica. For the purpose of comparison, five records obtained in different parts ofthe world were included in the study. As a mean ofidentif)'ing the damage potential ofthe records, the input energy as well as the plastic hysteretic energy speCtra were calculated for different levels of displacement ductility and a viscous damping coefficient $\sim=0.05$. The effect of duration of ground motion was studied by introducing the non dimensional parametery and the target ductility. $\mu$ TAR. The parametery is a function of the maximum displacement and the plastic hysteretic energy dissipation demands. The calculations were performed for single-degree-of-freedom systems with an elastoplastic hysteretic behavior. Other response quantities considered were the constant strength ductility demands and constant ductility strength demands. The results are contrasted with the current seismic design recommendations for the region as presented in the latest building codes available.

\section{INTRODUCTION}

For many years, researchers have sought simple ways to characterize the damage potential of earthquake ground motions (EQGMs). Although they have recognized that many ofthe characteristics of an EQGM (such as intensity, frequency content and duration) are important for estimating its damage potential, the majority of these characteristics have usually been ignored for the sake ofsimplicity. In this paper, consideration of these factors is attempted. However, it is necessary to point out that damage potential is not an absolute property ofan EQGM, and thus, the need arises to establish a frame ofreference. Attemps made to establish a frame ofreference by neglecting the dynamic characteristics of the structures subjected to the EQGM have lead to unreliable and inconsistent methods for the estimation of damage potential. In this paper, damage potential of an EQGM is measured according to its capacity to produce the failure of ductile reinforced concrete (RC) structures. To allow this, a reference frame is established using fundamental concepts of earthquake-resistant designo RC structures are modelled using single-degree-of-freedom systems (SDOFS) with elastoplastic (EPP) hysteretic behavior in which damage is estimated according to a damage index for RC members.

\section{DAMAGE POTENTIAL OF AN EARTH- QUAKE GROUND MOTION}

\section{Basic equation o/ Earthquake-Resistant De-} sign (EQ-RD). Our current EQ-RD procedures are based on a demand-supply relation. Relevant seismic demands on the structure need to be identified in such a way that they can be met by providing adequate seismic-resistant supplies. There are different types of seismic demands, and establishing what types are relevant for the EQ-RD of a given structure is not easy. The

\footnotetext{
* Universidad de Costa Rica, San José, Costa Rica

** Universidad Autónoma Metropolitana, México, D.F.
} 
previous statements can be formalized through the following equation, which identifies relevant aspects ofthe demand-supply approach:

$\begin{array}{cc}\text { DEMAND } & \text { SUPPLY } \\ 00 & \text { OC } \\ \text { Stiffoess } & \text { Stiffness } \\ \text { Streogth } & \text { Strength } \\ \text { Stability } & \text { Stability } \\ \text { Energy absortion } & \text { Energy absortion } \\ \text { andenergy } & \text { and energy } \\ \text { dissipation } & \text { dissipation } \\ \text { capacities } & \text { capacities }\end{array}$

$\mathrm{AH}$ aspects of eq. (1) usually need to be satisfied to achieve adequate EQ-RD [note that the displacement and deformability aspects of eq.(l) complement and are complemented by its stifTness and strength aspects, respectively). Traditionally, the energy aspect of eq.(l) has been ignored in EQ$\mathrm{RD}$; nevertheless, the possibility of using an energy demand-supply equation to improve EQ-RD has been suggested (Uang and Bertero 1988).

Absolute Energy Equation. Before establishing the relevance of energy demands in EQ-RD, it is necessary to obtain an energy equation capable of establishing the demand-supply balance of energy in an earthquake-resistant structure. For this purpose, consider the equation of motion of a viscously damped SDOFS subjected to horizontal EQGM:

$$
m v,+c i>+f s=0
$$

where $m$ is the mass ofthe SDOFS, e its damping coefficient, $f S$ its restoring force, $v$ the displacement of the mass relative to the ground, $\mathrm{vg}$ the ground displacement, and $V t=\mathrm{v}+\mathrm{vg}$ is the absolute displacement ofthe mass. By integrating eq.(2) with respect to $v(t)$ from $t=0$, the following is obtained:

$$
m:^{2}-J c v d v+J f s d v=J m v
$$

Equation (3) can be expressed as:

$$
E k+E m,+E a=E_{i}
$$

where $\mathrm{E}_{\mathrm{K}}$ is the absolute kinetic energy, $\mathrm{EH} \sim$ is the viscous damping energy, Ea the absorbed energy and El the absolute input energy. Note that Eacan be expressed as the sum of the plastic hysteretic energy $\left(\mathrm{E}_{\mathrm{H}} \mu\right)$ dissipated by the SDOFS plus the recoverable elastic strain energy (EEs) stored in the same system. Thus, eq.(4) can berewritten as:

$$
E k+E E S+E m, \quad+E_{H^{\mu}}=E_{i}
$$

A physically meaningful interpretation ofEı can be found by considering that El represents the work done by the total base shear at the foundation along the foundation's displacement (Uang and Bertero 1988). Uang and Bertero (1988) note that the energy equation can be expressed using an alternative formulation (relative energy equation); nevertheless they note that for the period range of practical interest ( $\mathrm{T}=0.3$ to $5 \mathrm{sec}$ ) the maximum value of El obtained using both formulations are very similar.

Equation (5) can be expressed as a demandsupply equation of energy by considering that $\mathrm{El}$ represents the energy demanded from the SDOFS while the sum of $\mathrm{E}_{\kappa}$. EEs, $\mathrm{EH}_{\mu}$ and $\mathrm{EH} \sim$ represents the energy supplied to that SDOFS. Note that the sum of $E_{K}$ and EEs is the energy stored in the SDOFS while the sum ofEH $\mu$ and $\mathrm{EH} \sim$ is the energy dissipated by the SDOFS. For rational EQ-RD, it is necessary to pro vide the structure with adequate supplies ofEH $\mu$ and $\mathrm{EH} \sim$ 'Although $\mathrm{E} \sim$ has become relevant in EQ-RD in recent years (given that some real structures are being provided with special energy dissipating devices such as viscoelastic dampers), this paper concentrates in the dissipation of $\mathrm{E}_{\mathrm{H}} \mu$. Note that $\mathrm{EH}_{\mu}$ dissipation and damage are closely related in RC members and structures, Le., $\mathrm{EH}_{\mu}$ dissipation implies nonlinear behavior which in turn implies damage in them.

Re damage indexes to establish damage potential o/ an EQGM using EH $\mu$ demands. Under load reversals well into the inelastic range, the strength of a RC member or structure will deteriorateo This deterioration ofthe mechanical characteristics and load-carrying capacity ofthe member or structure depends on the magnitude, sequence and number of inelastic incursions. A 
sound and rational EQ- RD procedure should provide means to estimate the strength and deformability capacity to be supplied to a structure so that it will not undergo excessive deterioration of its mechanical properties (or even failure) due to low-cycle fatigue. Sorne researchers have tried to relate low-cycle fatigue damage in $\mathrm{RC}$ members to the $\mathrm{E}_{\mathrm{H} \mu}$ demand imposed to those members. For this purpose, analytical relationships (damage indexes) that either implicitly or explicitly relate $\mathrm{E}_{\mathrm{H} \mu}$ to damage have been developed. A summary of several damage indexes can be found elsewhere (Chung et al. 1987).

Because of its simplicity, the Park and Ang damage index (Park et al. 1985), DMIpA' to estimate damage in RC beams and columns is used in this paper. In sorne cases, evaluatingDMIpA for SDOFS can provide valuable information to assess damage in RC buildings. Such is the case when the contribution ofupper modes is not relevant to the response of the building and damage is distributed uniformly among all the buildingls ductile members (i.e., beams for ductile RC frames). DMIpA is defined as:

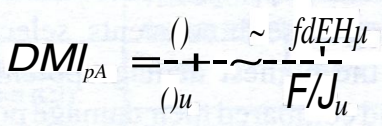

In eq.(6), 0 is the maximum displacement demand; Ou is the maximum displacement the member can undergo when subjected to monotonically increasing deformation; $F_{y}$ is the yield strength; and 13 is a parameter determined experimentally and ranging from -0.3 to 1.2 . From experimental calibration, a value of DMIpAless than or equal to 0.4 can be interpreted as repairable damage, from 0.4 to less than 1.0 as damage beyond repair, and larger than or equal to 1.0 as failure.

Defining the displacement ductility ratio, $\mu$, and the ultimate displacement ductility ratio under monotonically increasing deformation, $\mu \mathrm{u}$, as 0 and Ounormalized by the yield displacement, $0 y$, respectively (i.e., $\mu=0 / 0 \mathrm{y}$ and $\mu \mathrm{u}=\mathbf{o j} 0 \mathrm{y}$ ); and the normalized plastic hysteretic energy, $\mathrm{NE}_{\mathrm{H}} \mu$, as
$\mathrm{E}_{H} \mu$ normalized by Fy Oy (i.e., $\mathrm{NE}_{\mathrm{H} \mu}=\mathrm{EH}_{\mu} / \mathrm{F}$ y Oy), eq.(6) can be rewritten as follows:

$D M I_{P A}=\frac{\mu \delta_{y}}{\mu_{u} \delta_{y}}+\frac{\beta E_{H \mu}}{F_{y} \mu_{u} \delta_{y}}=\frac{\mu}{\mu_{u}}+\frac{\beta N E_{H \mu}}{\mu_{u}}$

and $D M I_{P A}=1 \Rightarrow \mu_{u}=\mu+\beta N E_{H \mu}$

Note that $\mu$ and $\mathrm{NE}_{\mathrm{H} \mu}$ are normalized measures of the 0 and $\mathrm{E}_{\mathrm{H} \mu}$ demands on the SDOFS, respectively. Equation $7 \mathrm{~b}$ is depicted graphically in Fig.1 (denoted as $\mathrm{DMIpA}=1$ ) within a $\mu$ vs. $\mathrm{NE}_{\mathrm{H}^{\mu}}$ Cartesian axis system. As shown, the $\mathrm{DMI}_{\mathrm{pA}}=1$ line delimits the no failure and failure zones. Note that $\mu<1$ (linear behavior) implies that $\mathrm{NE}_{\mathrm{H}} \mu=0$ (i.e., the response of a SDOFS can not fall in the shaded area 1 of Fig.l). Given that for monotonically increasing deformation $\mathrm{NE}_{\mathrm{H} \mu}=\mu-\mathrm{l}$, the value of $\mathrm{NE}_{\mathrm{H} \mu}$ carmot be smaller than $\mu$-1 (i.e., the response of a SDOFS cannot fall in the shaded area 2 of Fig.l).

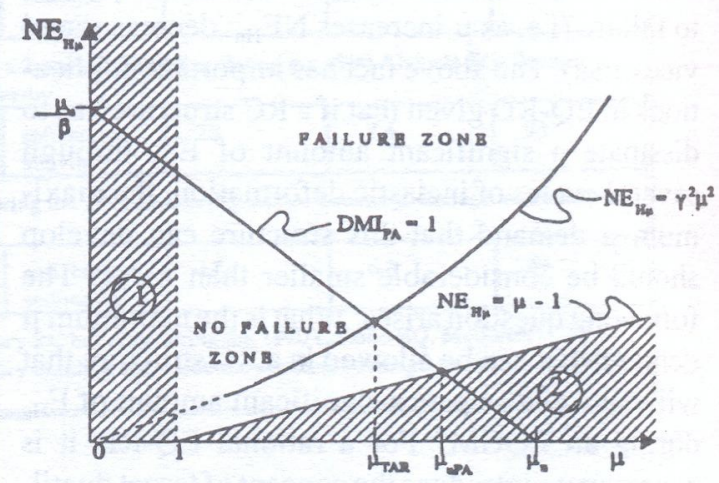

Fig.1 Definition offailure and no failure zone according to DMI.. = I

Sorne characteristics of DMIpA are worth noting. First, a value of 13 less than 0 does not have any physical meaning and is difficult to interpret. Second, the express ion estimates damage as a linear combination of 0 and $\mathrm{E}_{\mathrm{H}} \mu$ (or $\mu$ and $\mathrm{NE}_{\mathrm{H}} \mu$ ). When 0 and $\mathrm{E}_{\mathrm{H} \mu}$ are highly correlated(as in the case when the structure is loaded monotonically), the estimate of damage obtained using DMIpA is difficult to 
interpret. To illustrate this, note that a SDOFS subjected to monotonically increasing deformation will move along line $\mathrm{NE}_{\mathrm{H} \mu}=\mu-1$ (see Fig.l). Using DMIpA as a failure criteria in this case, the ultimate ductility that the SDOFS can develop is $\mu \mathrm{uPAwhich}$ as shown in Fig.l, is less than $\mu \mathrm{u}$. Nevertheless, undermonotonic loadingthe SDOFS would not fail until $\mu$ reaches a value equal to $\mu \mathrm{u}$. It can be concluded that DMIpA overestimates damage in SDOFS whose response falls close to line $\mathrm{NE}_{\mathrm{H} \mu}=\mu$-1. In spite ofthe above, DMIpAcan be used in several cases to characterize damage on $\mathrm{RC}$ members and structures. One important advantage ofusing DMIpA is that there is no need to know the way in which $\mathrm{E}_{\mathrm{H}^{\mu}}$ has been dissipated to estimate damage (although in sorne cases, this can lead to incorrect estimation of damage).

The use of damage indexes and energy demands in EQ-RD. The $\mathrm{E}_{\mathrm{H} \mu}$ dissipating capacity of a $\mathrm{RC}$ member or structure is not constant, as can be concluded by following the failure line DMIpA $=1$ in Fig.l. As shown, the larger the $\mu$ demand in the structure the smaller the $\mathrm{E}_{\boldsymbol{H}}$ that it can dissipate up to failure (i.e. as $\mu$ increases $\mathrm{NE}_{\mathrm{H} \mu}$ decreases and viceversa). The above fact has important implications in EQ-RD given that if a RC structure has to dissipate a significant amount of $\mathrm{E}_{\mathrm{H} \mu}$ through several cycles ofinelastic deformation, the maximum $\mu$ demand that this structure can develop should be considerable smaller than its $\mu \mathrm{u}$. The following question arises: What is the maximum $\mu$ demand that can be allowed in a RC structure that will have to dissipate a significant amount of $\mathrm{E}_{\mathrm{H} \mu}$ during an EQGM? For a rational EQ-RD it is necessary to introduce the concept oftarget ductility ( $\mu \mathrm{TAR}), w h i c h$ is the maximum value of $\mu$ that a $\mathrm{RC}$ structure can develop given that its $\mathrm{E}_{\mathrm{H} \mu}$ dissipating capacity meets (is greater or equal to) its corresponding demando Fajfar et al. (1992) have introduced a factor to allow for a simple method to evaluate $\mu \mathrm{TAR}$ :

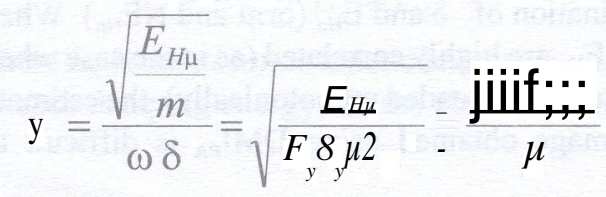

It has been observed that the $\mathrm{y}$ factor tends to increase for EQGMs with longer duration, but it is a very stable quantity for a given EQGM, i.e., it is fairly independent of the value of $\mu$ (or strength) that the SDOFS develops and its viscous damping coefficient, S, (Fajfar et al. 1992). From eq.(8) it can be concluded that $\mathrm{NE}_{\mathrm{H} \mu}=$ y2 $\mu 2$. This parabola is depicted in Fig.l, where a graphical interpretation of $\mu$ TARs given. It should be noted that $\mathrm{y}$ is fairly insensitive to the value of $\mu$ only for moderate and high values of $\mu$ (i.e., $\mu ;:: 2$ ), given that if the $\mu$ demand in a SDOFS tends to 1 , the value of $y$ tends to 0 . In Fig.1, this is schematically shown by plotting in continuous line the $\mathrm{NE}_{\mathrm{H} \mu}=y 2 \mu 2$ curve in the region of $\mu$ where $\mathrm{y}$ is stable with respect to $\mu$, and in discontinuous line where it is not.

\section{RESPONSE SPECTRA OF SDOFS SUB- JECTED TO SELECTED EQGMs}

Selected Earthquake Ground Motions. In recent years, three relevant seismic events have occurred in Costa Rica: 1990 Cóbano EQ, 1990 Alajuela EQ and 1991 Limón EQ. The authors evaluated the damage potential of several EQGMs recorded during these three events, selected the EQGM with the highest damage potential for each event, and compared their damage potential against that of other well-known recorded EQGMs. Table 1 summarizes the EQGMs selected to carry out this comparison plus relevant information about them.

Constant Ductility. Figure 2 shows the response spectra ofEPP SDOFS in which $\mu=1$ and 4 and $\mathrm{S}=0.05$. The following demands were considered:

- Strength, $\left(\mathrm{Sa} / \mathrm{g}\right.$ or $\left.\mathrm{c}_{\mathrm{y}}\right)$. With the exception of $\mathrm{C} 1$ and short period $(\mathrm{T})$, the elastic Salg demand ofthe Costa Rica EQGMs is considerably smaller than that of the world's EQGMs (Fig.2a). $\mathrm{CH}$ and $\mathrm{Nr}$ have very high elastic Salg demand for short T; while that of $\mathrm{Mx}$ is the largest for longer periods (although Mx has very small demands for short T). The elastic Salg demands ofNr are also significant for long $\mathrm{T}$. As shown Jp and 
TABLE 1.General inCormation oC the EQGMs used in these paper

\begin{tabular}{|c|c|c|c|c|}
\hline \multirow[t]{2}{*}{ EQOM } & \begin{tabular}{l|l} 
l'eDk ground & Effective \\
acceleralion & "."-"k. ace."'
\end{tabular} & $\begin{array}{l}\text { Damogc } \\
\text { Potential'.. }\end{array}$ & $\begin{array}{l}\text { Soil } \\
\text { Condition }\end{array}$ & Mngnitude. \\
\hline & \multicolumn{4}{|c|}{ Seismic cvent qurin2, which il was recorded and dama2C obscrved ncnr recordin - sile } \\
\hline \multirow{2}{*}{$\begin{array}{l}\text { Secretaria } \\
\text { deeomuni- } \\
\text { c:ac:iones y } \\
\text { Transporte } \\
\text { E-W(MXI }\end{array}$} & $0.08 \mathrm{~g}$ & 122.8 & sonday & 39 \\
\hline & \multicolumn{4}{|c|}{$\begin{array}{l}\text { This EQGM was recordcd in a parking } 101 \text { localcd in !he lake zone ol Mcxico eily during!he } 1985 \text { Mexico EQs. } \\
\text { Sevcre damage and cven collapse of RC strUclures were observed nenrby. }\end{array}$} \\
\hline \multirow{2}{*}{$\begin{array}{l}\text { Miyagi- } \\
\text { Km-Oki } \\
\text { N-S (Jp) }\end{array}$} & 0.118 & 12.9 & aUuvium & 100 \\
\hline & \multicolumn{4}{|c|}{$\begin{array}{l}\text { This EQGM wu recorded allhe base of 9-.lory RC building in Tohoku Universily during Ibc } 1918 \text { Japan EQ. } \\
\text { Minor d:Ima2c vas observed in Ibe 9-slorv, buildin2 }\end{array}$} \\
\hline \multirow[t]{2}{*}{$\begin{array}{l}\text { LloUco } \\
\text { NIOE } \\
(\mathrm{eH})\end{array}$} & $0.51 \mathrm{~g}$ & 22.1 & $\begin{array}{l}\text { sandslone } 8 \\
\text { volcanic } \\
\text { roek }\end{array}$ & \begin{tabular}{l|l|l}
36 & 1.8 & 5
\end{tabular} \\
\hline & \multicolumn{4}{|c|}{$\begin{array}{l}\text { This EQGM was recorded al !he basc of a .chool building during Ihe } 1985 \text { Chilcan EQ. Moderate structural } \\
\text { daml2c in Re strUClUres was observed ncarbv. }\end{array}$} \\
\hline \multirow{2}{*}{$\begin{array}{l}\text { Sylmnr } \\
\text { Packing Lot } \\
\text { N-S (Nr) }\end{array}$} & $0.57 \mathrm{~g}$ & 16.8 & aUuvium & $\begin{array}{llll}S & 16.7 & 1 S \\
\end{array}$ \\
\hline & \multicolumn{4}{|c|}{$\begin{array}{l}\text { This EQGM was reconlcd in a paclcing 101during Ihe } 1994 \text { Northridge EQ. Scrcre slrUctural and nonslnJCIUral } \\
\text { damal!c on RC and sleel .IruclUrcs were observed nearbv, }\end{array}$} \\
\hline \multirow{2}{*}{$\begin{array}{l}\text { Emetyville } \\
260 \text { (LP) }\end{array}$} & I NA & NA & bavmud & \begin{tabular}{l|l|l|l}
9 & 6.9 & 97 \\
\end{tabular} \\
\hline & \multicolumn{4}{|c|}{$\begin{array}{l}\text { This EQGM was recorded } 100 \mathrm{fl} \text { away from a } 30 \text {-story RC building located in !he San Francisco Bay Area during } \\
\text { !he } 1989 \text { Loma Pricta EO. The } 30 \text {-SlOlV buildin. suffered li2ht strUclUral and nonslrUClural damo2e }\end{array}$} \\
\hline \multirow[t]{2}{*}{$\begin{array}{l}\text { Alajuelo } \\
\text { E-W(CI) }\end{array}$} & NA & 4.4 & $\begin{array}{l}\text { firmsoil, } \\
\text { volcanic } \\
\text { denosits }\end{array}$ & \begin{tabular}{l|l|l}
10 & 6.1 & 20
\end{tabular} \\
\hline & \multicolumn{4}{|c|}{$\begin{array}{l}\text { Thi. EQGM was rccorded in the ground levcl of a } 2 \text {-slory RC building during the } 1 \mathrm{~m} \text { Alajuela EQ. Scverc } \\
\text { damaltc was obperved in RC structures locoled nearbv. }\end{array}$} \\
\hline \multirow[t]{2}{*}{$\begin{array}{l}\text { Cartago } \\
\text { N-S (C2) }\end{array}$} & $0.20 \mathrm{~g}$ & 3 & $\begin{array}{l}\text { Sofr, recent } \\
\text { aUuvium }\end{array}$ & \begin{tabular}{l|l|l}
28 & 7.4 & 93
\end{tabular} \\
\hline & \multicolumn{4}{|c|}{$\begin{array}{l}\text { This EQGM was recorded allhe eentr.ll Par!< during !he } 1991 \text { Limón EQ. Minor strUClural datnage wiss observed } \\
\text { in Re buildin } 2 \text { s located nearbv, }\end{array}$} \\
\hline \multirow[t]{2}{*}{$\begin{array}{l}\text { Puntarcnas } \\
\text { B-W(e3) }\end{array}$} & $0.21 \mathrm{~g}$ & 3.9 & $\begin{array}{l}\text { soft, coutal } \\
\text { sedimenls }\end{array}$ & \begin{tabular}{l|ll}
17 & 6.8 & 49
\end{tabular} \\
\hline & \multicolumn{4}{|c|}{$\begin{array}{l}\text { This EQGM was recorded allhe base of a } 100 \text { sIory RC building during!he } 1 \mathrm{~m} \text { Cóbano EQ. Moderate } \\
\text { nonslrUclural damage was observed in Ihc } 10 \text {-slOry building and moderate slrUClUral damagc was observed in RC } \\
\text { buildinu located nearbv. }\end{array}$} \\
\hline
\end{tabular}

(1) according 10 ATe 3-06 (1978)

(2) according 10 Araya and Saragoni (1984), unilS: $\mathrm{cm} \mathrm{x} \mathrm{sec} 3$

(3) s trong motian duration according to Trifunac and Brady (1975)

LP have significant elastic Sa/g demand for $\mathrm{T}$ around 1 and $1.5 \mathrm{sec}$, respectively. Similar tendencies as those discussed above can be observed for $\mu=4$ in Fig.2c; nevertheless, it is interesting to note that for longer $\mathrm{T}(\mathrm{T} \sim 1.8 \mathrm{sec})$, $\mathrm{Mx}$ and $\mathrm{Nr}$ have similar S./g demands.

Absolute input energy, El' As shown in Fig.2b, the elastic El demands ofthe Costa Rica EQGMs are considerably smallerthan those ofthe world's
EQGMs. In spite ofits large S.lg demands, the elastic Eldemands for $\mathrm{Nr}$ are considerably smaller than those ofCH in the short $\mathrm{T}$ range and are considerably smaller than those of $\mathrm{Mx}$ for longer $\mathrm{T}$. Of all EQGMs, $\mathrm{Mx}$ has the largest value of maximum elastic El' The elastic El demands ofJp and LP are important for T""1 and $1.5 \mathrm{sec}$, respectively. Similar tendencies can be seen for $\mu=4$ in Fig.2d, although as shown, 

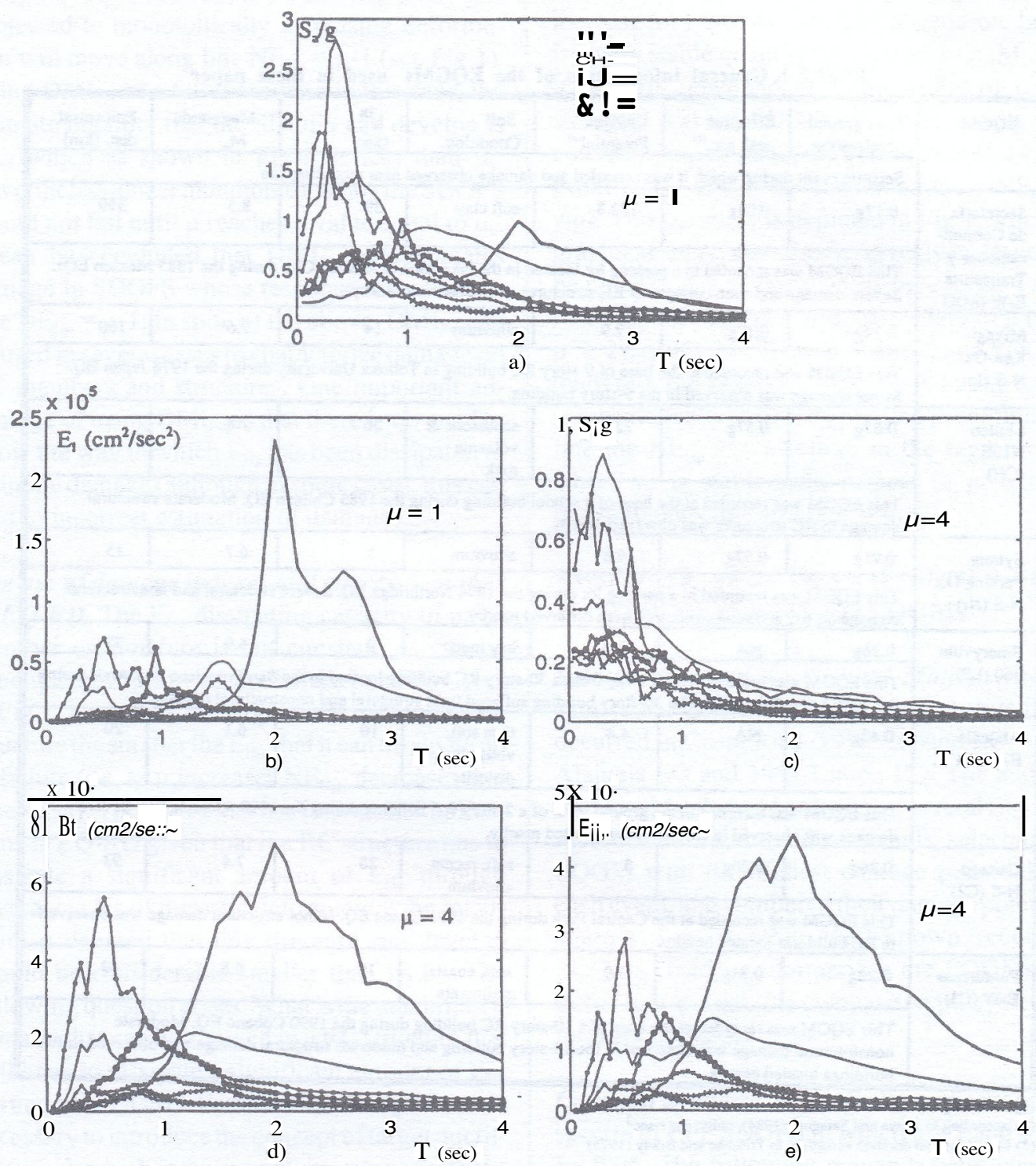

Fig.2 Constant ductility response spectra for EPP SDOFS subjeted to selected to selected EQGMs

the maximum value of $\mathrm{E}_{\mathrm{i}}$ for $\mathrm{CH}$ and $\mathrm{Mx}$ are similar.

Plastic hysteretic energy, $\mathrm{E}_{\mathrm{H} \mu}$. As shown in Fig.2e, the $\mathrm{E}_{\mathrm{H} \mu}$ demands for $\mu=4$ of the Costa Rica EQGMs are considerably smaller than those of the world's EQGMs. Similar tendencies than those described for $\mathrm{El}$ and $\mu=4$ (Fig.2d) can be observed in Fig.2e for $\mathrm{E}_{\mathrm{H} \mu}$ and $\mu=4$; nevertheless, it can be ob- served that the maximum demand $\mathrm{ofE}_{\mathrm{H}} \mu$ for $\mathrm{Mx}$ becomes about twice that of $\mathrm{CH}$.

The study ofthe above demands suggests that the damage potential of the recorded Costa Rica EQGMs is considerably lower than that of the world's EQGMs. Within the world's EQGMs, three seem to have very large damage potential (although with very different characteristics): $\mathrm{Mx}$ has large S.lg and energy demands for large $\mathrm{T} ; \mathrm{Nr}$ 

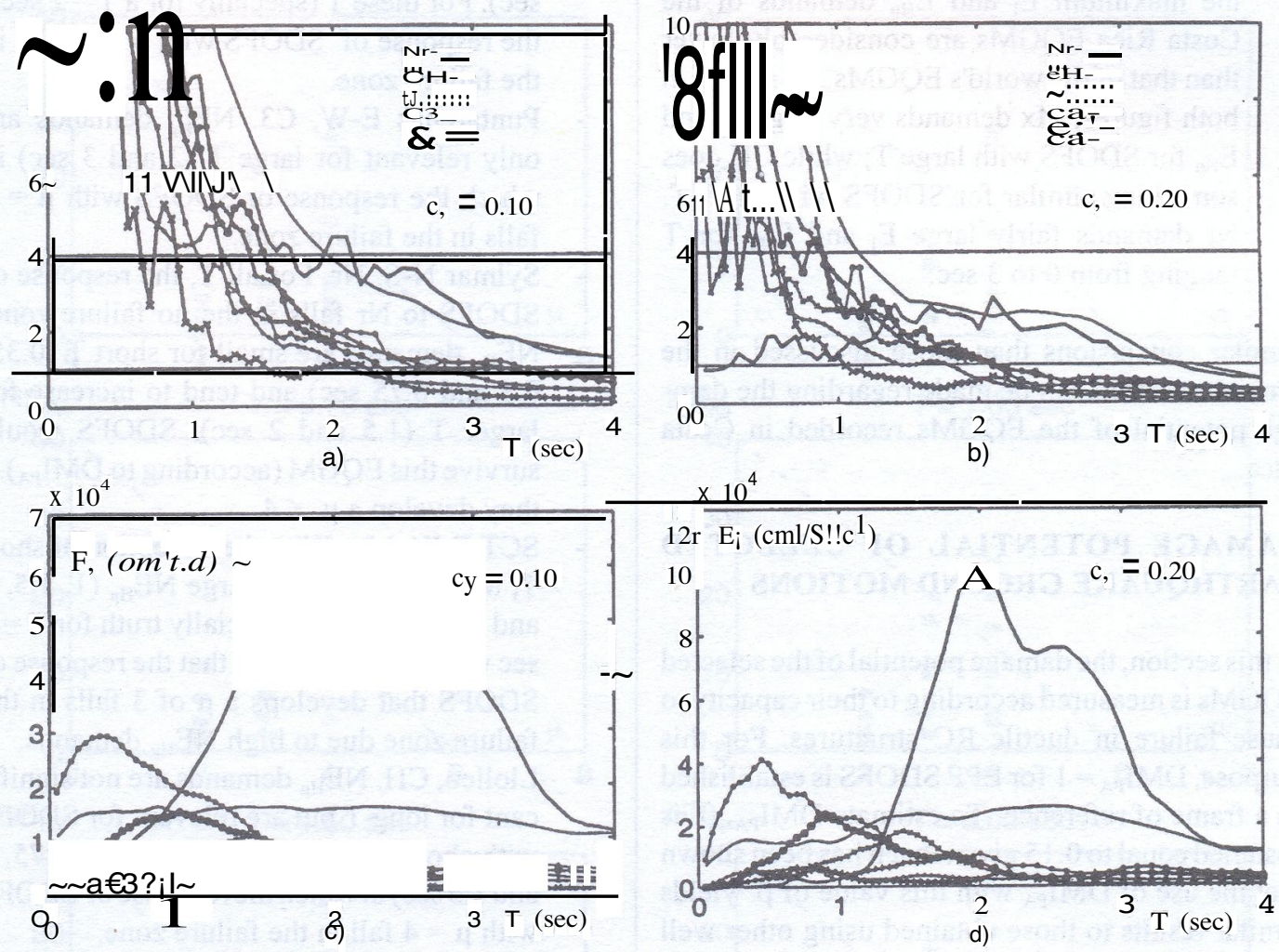

$\times 10^{4}$
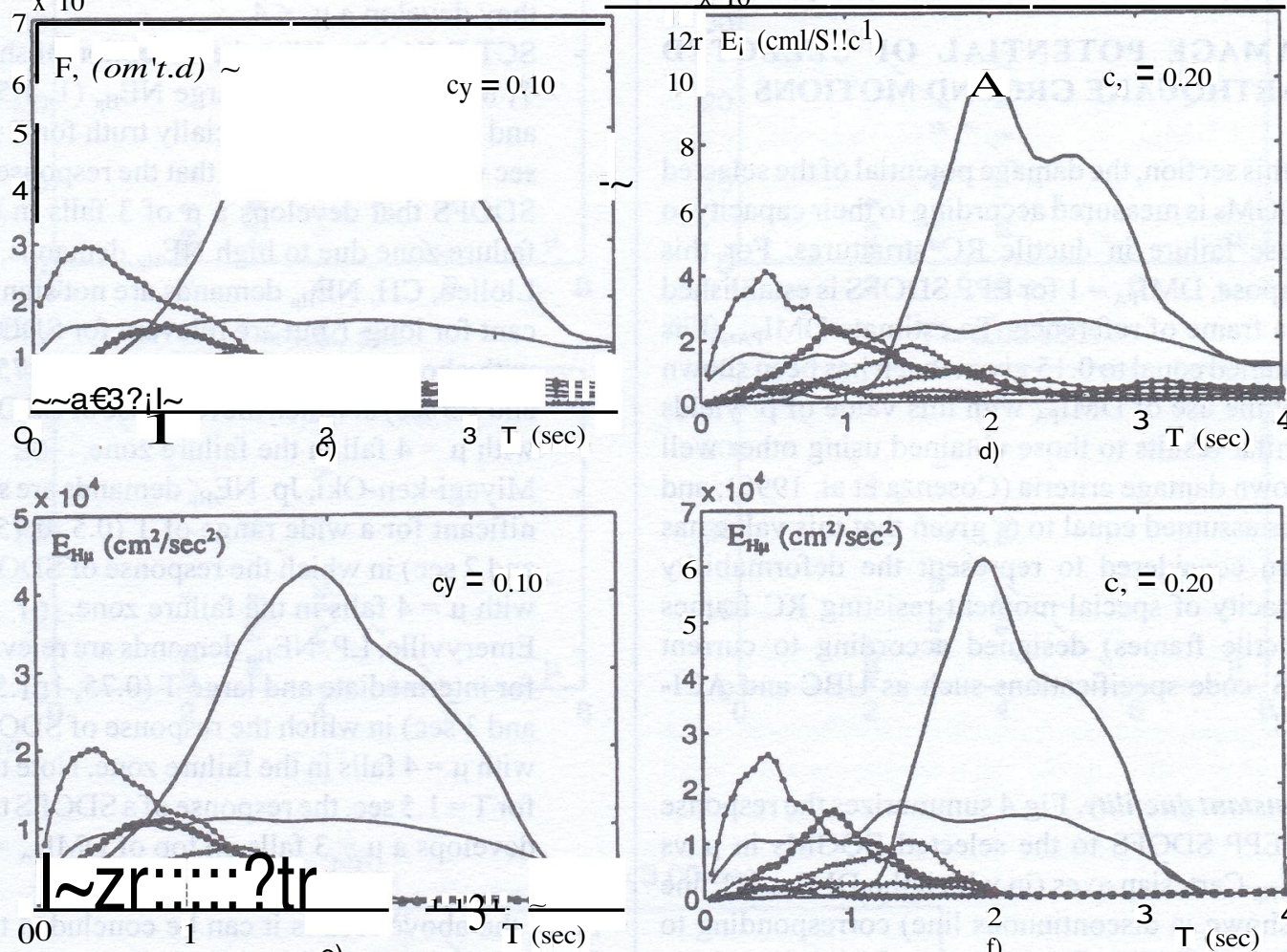

e)

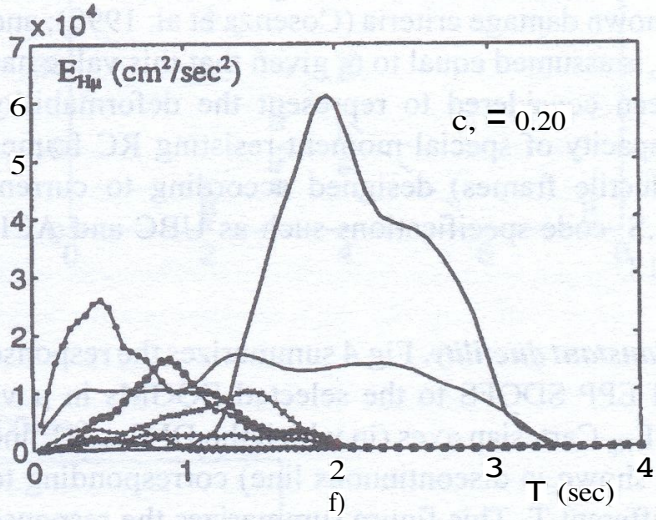

Fig.3 Constant strength responde spectra for EPP SDOFS subjeted to selected EQGMs

has very large Sjg demands over the whole $\mathrm{T}$ range under study (especially for short $\mathrm{T}$ ) but has small energy demands; $\mathrm{CH}$ has large $\mathrm{Sjg}$ and significant energy demands for short $\mathrm{T}$.

Constant Strength. Figure 3 shows the response spectra ofEPP SDOFS with $c_{y}=0.1$ and $c_{y}=0.2$ and $\sim=0.05$. The following response quantities were considered:
- Ductility, $\mu$. As shown in Figs.3a and 3b, Nr has in general the largest $\mu$ demands, except :orlongerT,inwhichMxhascomparableand $\mathrm{m}$ some cases larger $\mu$ demands. In general the Costa Rica EQGMs have smaller $\mu$ demands throughout the whole $\mathrm{T}$ range under study.

- Input energy, Eh and plastic hysteretic energy, $\mathrm{EH} \mu$-As shown in Figs.3c, 3d, 3e and 3f, 
the maximum $\mathrm{El}$ and $\mathrm{E}_{\mathrm{H} \mu}$ demands of the Costa Rica EQGMs are considerably lower than that ofthe world's EQGMs. As shown in both figures, $\mathrm{Mx}$ demands very large $\mathrm{El}$ and $\mathrm{E}_{\mathrm{H} \mu}$ for SDOFS with large $\mathrm{T}$; while $\mathrm{CH}$ does something similar for SDOFS with short $\mathrm{T}$. $\mathrm{Nr}$ demands fairly large $\mathrm{El}$ and $\mathrm{E}_{\mathrm{H} \mu}$ for $\mathrm{T}$ ranging from 0 to 3 seco

Similar conclusions than those discussed in the previous section can be made regarding the damage potential of the EQGMs recorded in Costa Rica.

\section{DAMAGE POTENTIAL OF SELECTED EARTHQUAKE GROUND MOTIONS}

In this section, the damage potential ofthe selected EQGMs is measured according to their capacity to cause failure in ductile RC structures. For this purpose, $\mathrm{DMlpA}=1$ for EPP SDOFS is established as a frame ofreference. To estimate DMIpA' $P$ is assumed equal to 0.15 given that it has been shown that the use of DMIpA with this value of $P$ yields similar results to those obtained using other well known damage criteria (Cosenza et al. 1990); and $\mu$ uis assumed equal to 6 , given that this value has been considered to represent the deformability capacity of special moment-resisting RC frames (ductile frames) designed according to current U.S. code specifications such as UBC and ACI318.

Constant ductility. FigA summarizes the response of EPP SDOFS to the selected EQGMs in $\mu$ vs $\mathrm{NE}_{\mathrm{H} \mu}$ Cartesian axes (in which the $\mathrm{DMlpA}=1$ line is shown in discontinuous line) corresponding to different $T$. This figure summarizes the response ofSDOFS with $=0.05$ and developing a $\mu$ of 2,3 and 4. Note that the strength demand varies from EQGM to EQGM for a given value of $\mu$. The following can be observed:

Alajuela E-W, C 1. $\mathrm{NE}_{\mathrm{H} \mu}$ demands are relevant for short $\mathrm{T}(0.35$ and $0.5 \mathrm{sec})$ in which the response of SDOFS with $\mu=4$ falls in the failure zone. $\mathrm{NE}_{\mathrm{H} \mu}$ becomes relevant again for a $\mathrm{T}$ of 2 seco

- Cartago N-S, C2. $\mathrm{NE}_{\mathrm{H} \mu}$ demands are relevant for intermediate and long $\mathrm{T}(0.75,1$ and 2 sec). For these $\mathrm{T}$ (specially for a $\mathrm{T}=2 \mathrm{sec}$ ), the response of SDOFS with $\mu=4$ falls in the failure zone.

- Puntarenas E-W, C3. $\mathrm{NE}_{\mathrm{H} \mu}$ demands are only relevant for large $\mathrm{T}$ (2 and $3 \mathrm{sec})$ in which the response of SDOFS with $\mu=4$ falls in the failure zone.

- Sylmar N-S, Nr. For all T, the response of SDOFS to $\mathrm{Nr}$ falls in the no failure zone. $\mathrm{NE}_{\mathrm{H}} \mu$ demands are small for sh,Prt $\mathrm{T}(0.35$, 0.5 and $0.75 \mathrm{sec}$ ) and tend to increase for larger $\mathrm{T}$ (1.5 and $2 \mathrm{sec})$. SDOFS would survive this EQGM (according to DMIpA)if they develop a $\mu$ :::4.

- SCT E-W, Mx. With the exception ofshort $\mathrm{T}, \mathrm{Mx}$ demands very large $\mathrm{NE}_{\mathrm{H} \mu}(1,1.5,2$ and $3 \mathrm{sec}$ ). This is especially truth for $\mathrm{T}=2$ sec where it can be seen that the response of SDOFS that develops a $\mu$ of 3 falls in the failure zone due to high $\mathrm{NE}_{\mathrm{H} \mu}$ demands.

- Llolleo, $\mathrm{CH}$. $\mathrm{NE}_{\mathrm{H} \mu}$ demands are not significant for long $\mathrm{T}$ but are relevant for SDOFS with short and intermediate $\mathrm{T}(0.5,0.75,1$ and $1.5 \mathrm{sec}$ ) in which the response of SDOFS with $\mu=4$ fall in the failure zone.

- Miyagi-ken-Oki, Jp. $\mathrm{NE}_{\mathrm{H}^{\mu}}$ demands are significant for a wide range ofT $(0.5,0.75,1$ and $2 \mathrm{sec}$ ) in which the response ofSDOFS with $\mu=4$ falls in the failure zone.

- Emeryville, LP. $\mathrm{NE}_{\mathrm{H} \mu}$ demands are relevant for intermediate and large $\mathrm{T}(0.75,1,1.5,2$ and $3 \mathrm{sec}$ ) in which the response ofSDOFS with $\mu=4$ falls in the failure zone. Note that for $\mathrm{T}=1.5 \mathrm{sec}$, the response of a SDOFS that develops a $\mu=3$ falls on top of $\mathrm{DMIpA}=1$.

From the above results it can be concluded that for practically all the EQGMs under study (with the exception of $\mathrm{Nr}$ ), $\mathrm{NE}_{\mathrm{H} \mu}$ demands become relevant for the failure of SDOFS that develop a $\mu$ of 4 (although the $\mathrm{T}$ region in which this happens varies from EQGM to EQGM). From this point ofview $\mathrm{Nr}$ shows small damage potential while $\mathrm{Mx}$ and LP (in which even the response ofSDOFS developing a $\mu$ of 3 falls in the failure zone for $\mathrm{T}$ of 1.5 and $2 \mathrm{sec}$ ) have large damage poten tial. Different Costa Rica EQGMs show large damage potential in different $\mathrm{T}$ range; nevertheless, it is interesting to note that all 3 have significant $\mathrm{NEH} \mu$ demands for $\mathrm{T}$ of 2 seco 

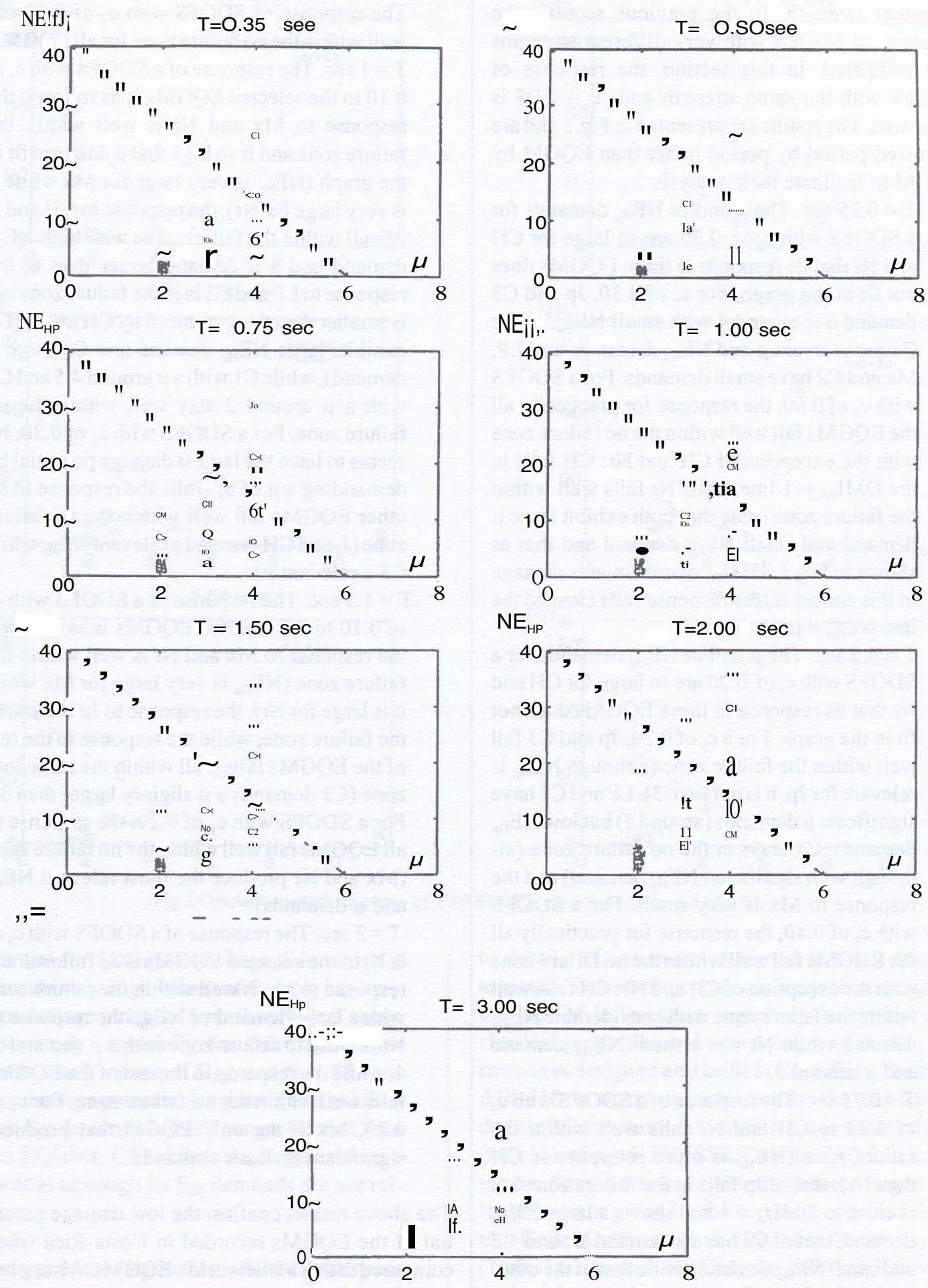

Fig.4 Constant ductility response ofEPP SDOFS subjeted to selected EQGMs 
Constant strength. In the previous section, the response of SDOFS with very different strengths was compared. In this section, the response of SDOFS with the same strength and $\sim=0.05$ is compared. The results are presented in Fig.5 and are discussed period by period rather than EQGM by EQGM to facilitate their analysis:

- $\mathrm{T}=0.35$ seco The $\mu$ aocl/or $\mathrm{NE}_{\mathrm{H}} \mu$ demands for a SDOFS with cyof 0.30 are so large for $\mathrm{CH}$ and $\mathrm{Nr}$ that its response to these EQGMs does not fit in the graph. For cy of 0.30, Jp and C3 demand a $\mu$ around 4 with small $\mathrm{NE}_{\mathrm{H}} \mu$, while $\mathrm{C} 1$ has relevant $\mu$ and $\mathrm{NE}_{\mathrm{H}} \mu$ demands, and $\mathrm{LP}$, $\mathrm{Mx}$ and $\mathrm{C} 2$ have small demands. For a SDOFS with cyofO.60, the response for practically all the EQGMs fall well within the no failure zone with the exception of $\mathrm{CH}$ and $\mathrm{Nr}$ : $\mathrm{CH}$ falls in the $\mathrm{DMI}_{\mathrm{pA}}=1$ line while $\mathrm{Nr}$ falls well within the failure zone (note that both exhibit large $\mu$ demand and small $\mathrm{NE}_{\mathrm{H} \mu}$ démand and that as shown in Fig.1, DMI $\mathrm{pA}_{\mathrm{pA}}$ overestimates damage in this zone, i.e., the response falls c10se to the line $\left.\mathrm{NE}_{\mathrm{H} \mu}=\mu-1\right)$.

- $\mathrm{T}=0.5$ seco The $\mu$ aocl/or $\mathrm{NE}_{\mathrm{H}} \mu$ demands for a SDOFS with cyof 0.20 are so large for $\mathrm{CH}$ and $\mathrm{Nr}$ that its response to these EQGMs does not fit in the graph. For a cyof0.20, Jp and C3 fall well within the failure zone (although $\mathrm{NE}_{\mathrm{H} \mu}$ is relevant for $\mathrm{Jp}$, it is not for $\mathrm{C} 3$ ), $\mathrm{LP}$ and $\mathrm{C} 2$ have significant $\mu$ demands (around 5) but low $\mathrm{NE}_{\mathrm{H}} \mu$ demands, $\mathrm{Cl}$ stays in the no failure zone (although with significant $\mathrm{NE}_{\mathrm{H}} \mu$ demand) and the response to $\mathrm{Mx}$ is very small. For a SDOFS with cyofO04O, the response for practically all the EQGMs fall well within the no failure zone with the exception ofCH and $\mathrm{Nr}$ : $\mathrm{CH}$ falls well within the failure zone with considerable $\mathrm{NE}_{\mathrm{H}} \mu$ demand while $\mathrm{Nr}$ has a small $\mathrm{NE}_{\mathrm{H} \mu}$ demand and $\mu$ around 5 .

- $T=0.75$ secoThe response ofa SDOFS with cy of 0.20 to $\mathrm{CH}$ and $\mathrm{Nr}$ falls well within the failure zone $\left(\mathrm{NE}_{\mathrm{H} \mu}\right.$ is more relevant for $\mathrm{CH}$ than $\mathrm{Nr}$ ), that of $\mathrm{Jp}$ falls in the failure zone but is close to $\mathrm{DMI}_{\mathrm{PA}}=1$ and shows a large $\mathrm{NE}_{\mathrm{H}}{ }^{\mu}$ demand, that ofC 3 has a $\mu$ demand around 4.5 and small $\mathrm{NE}_{\mathrm{H}}$ demand, while that ofthe other EQGMs falls well within the no failure zone.
The response of SDOFS with cy of 0040 fall well within the no failure zone for all EQGMs.

- $T=1$ secoThe response of a SDOFS with cyof 0.10 to the selected EQGMs is as follows: the response to $\mathrm{Mx}$ and $\mathrm{Nr}$ is well within the failure zone and is so high that it does not fit in the graph $\left(\mathrm{NE}_{\mathrm{H} \mu}\right.$ is very large for Mx while $\mu$ is very large for $\mathrm{Nr}$ ), the response to $\mathrm{CH}$ and $\mathrm{J}_{\mathrm{p}}$ is well within the failure zone with high $\mathrm{NE}_{H} \mu$ demand and a $\mu$ demand larger than 6 , the response to $\mathrm{LP}$ and $\mathrm{C} 3$ is in the failure zone but is smaller than that produced by $\mathrm{CH}$ and $\mathrm{J}_{\mathrm{p}}(\mathrm{LP}$ exhibits large $\mathrm{NE}_{\mathrm{H} \mu}$ demand and $\mathrm{C} 3$ large $\mu$ demand), while $\mathrm{C} 1$ with a $\mu$ around 4.5 and $\mathrm{C} 2$ .with a $\mu$ around 2 stay well within the no failure zone. For a SDOFS with cyofO.20, $\mathrm{Nr}$ seems to have the largest damage potential by demanding a $\boldsymbol{\mu}$ of 5 ; while the response to all other EQGMs fall well within the no failure zone $\left(\mathrm{J}_{\mathrm{p}}\right.$ and $\mathrm{CH}$ demand a relevant $\mathrm{NE}_{\mathrm{H}} \mu$ while C3 a relevant $\mu$ ).

$\mathrm{T}=1.5$ seco The response of a SDOFS with cy of $0.1 \mathrm{O}$ to the selected EQGMs is as follows: the response to $\mathrm{Mx}$ and $\mathrm{Nr}$ is well within the failure zone $\left(\mathrm{NE}_{\mathrm{H} \mu}\right.$ is very large for $\mathrm{Mx}$ while $\mu$ is large for $\mathrm{Nr}$ ), the response to $\mathrm{Jp}$ is close to the failure zone, while the response to the rest ofthe EQGMs falls well within the no failure zone (C3 demands a $\boldsymbol{\mu}$ slightly larger than 3 ). For a SDOFS with cy ofO.20, the response to all EQGMs fall well within the no failure zone ( $\mathrm{Mx}$ and $\mathrm{Nr}$ produce the most relevant $\mathrm{NE}_{\mathrm{H}} \mu$ and $\mu$ demands).

- $\mathrm{T}=2$ secoThe response ofa SDOFS with cyof 0.10 to the selected EQGMs is as follows: the response to $\mathrm{Mx}$ is well within the failure zone with a large demand of $\mathrm{NE}_{\mathrm{H} \mu}$, the response to $\mathrm{Nr}$ is c10se to failure zone with a $\mu$ demand of 4 , while the response to the rest ofthe EQGMs falls well within the no failure zone. For cy of $0.20, \mathrm{Mx}$ is the only EQGM that produces significant inelastic demands.

The above results confirm the low damage potential of the EQGMs recorded in Costa Rica when compared to that ofthe world's EQGMs. Also, it has been confirmed that: Mx has a very large damage 

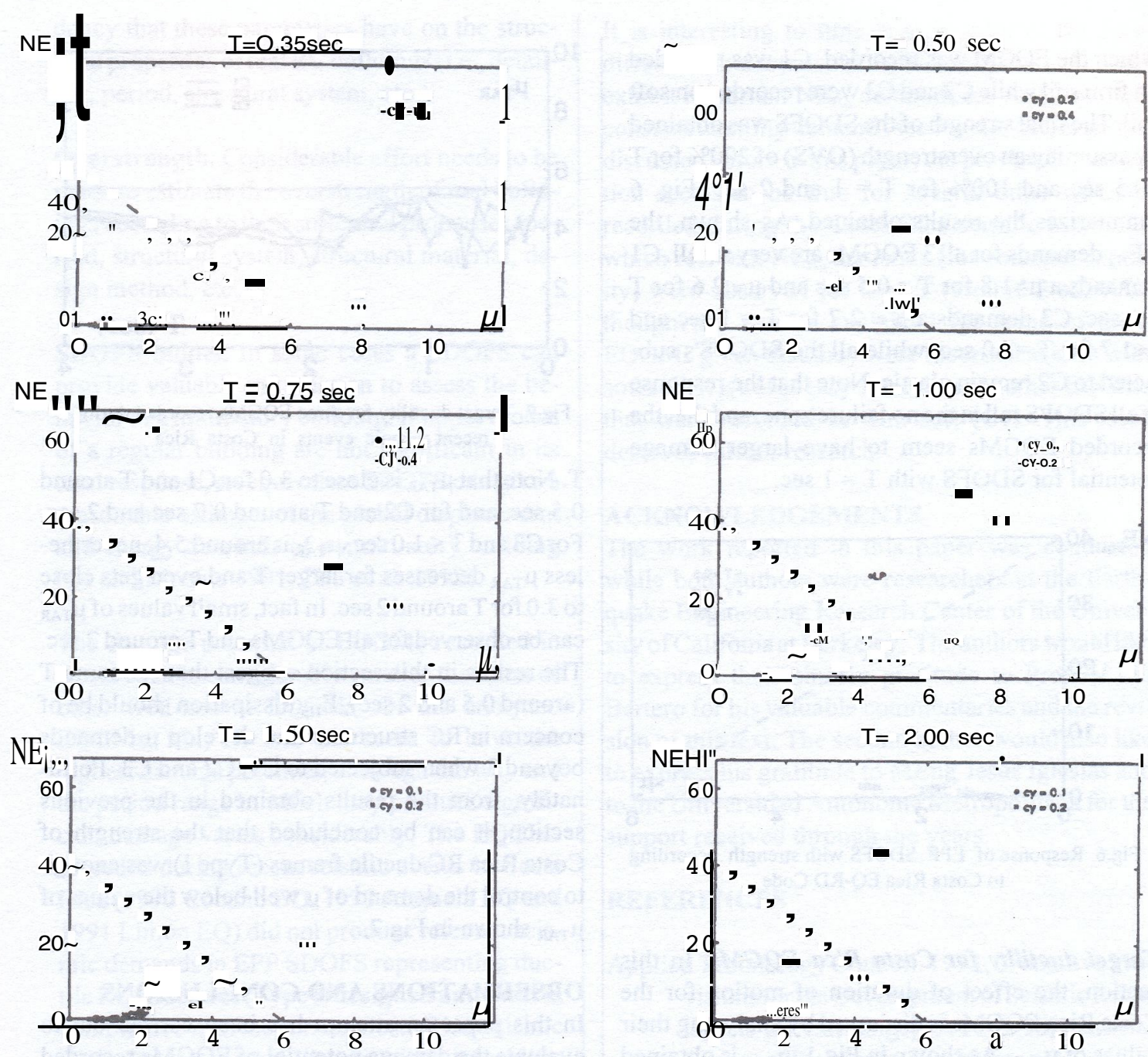

Fig.5 Constant strength response of EPP SDOFS subjeted to selected EQGMs

potential for SDOFS with large $\mathrm{T}$ in which it demands very high values of $\mathrm{E}_{\mathrm{H}} \mu$; $\mathrm{Nr}$ has very large damage potential over the whole $\mathrm{T}$ range under study (especially for short $\mathrm{T}$ ) but demands small values of $\mathrm{E}_{\mathrm{H}} \mu$; and that $\mathrm{CH}$ has large damage potential for short $\mathrm{T}$ and exhibits large $\mathrm{E}_{\mathrm{H} \mu}$ demands in this $\mathrm{T}$ range. Ofthe Costa Rica EQGMs, C3 exhibits the largest damage potential although its $\mathrm{E}_{\mathrm{H} \mu}$ demands are not relevant.

Strength according to Costa Rica EQ-RD provisions. In this section, an attempt to estimate the damage potential ofthe Costa Rica EQGMs to ductile RC structures designed in Costa Rica is assessed. This attempt can only be qualitative given the lack of information regarding the typical mechanical properties and overstrength of ductile RC structures designed and buílt in Costa Rica. Because ACI-318 is currently enforced for the EQ-RD of ductile RC structures in Costa Rica, it is assumed that $\sim=0.15$ and $\mu \mathrm{u}=6$. EPP SDOFSwith $\mathrm{T}=0.5,1$, and 2 sec are designed to have a strength according to the specifications given by the current Costa Rica Seismic Code (Gutiérrez et al. 1987) for ductile frames (Type 1). For each EQGM, the EPP SDOFS were designed according to the soil condition and seismic coefficient (S.lg) corresponding to the location at 
which the EQGM was recorded. $\mathrm{C} 1$ was recorded on firm soil while $\mathrm{C} 2$ and $\mathrm{C} 3$ were recorded on soft soil. The final strength ofthe SDOFS was obtained by assuming an overstrength (OVS) of $200 \%$ for T $=0.5 \mathrm{sec}$ and $100 \%$ for $\mathrm{T}=1$ and 2 seco Fig. 6 summarizes the results obtained. As shown, the $\mathrm{NE}_{\mathrm{H} \mu}$ demands for aU3 EQGMs are very small. C 1 demands a $\mu^{\prime \prime}, 1.8$ for $\mathrm{T}=0.5 \mathrm{sec}$ and $\mu$ "" 2.6 for $\mathrm{T}$ $=1 \mathrm{sec}, \mathrm{C} 3$ demands a $\mu " " 2.7$ for $\mathrm{T}=1 \mathrm{sec}$ and $\mu " " 1.7$ for $\mathrm{T}=2.0 \mathrm{sec}$, while aU the SDOFS's subjected to $\mathrm{C} 2$ remain elastic. Note that the response of aUSDOFS fall in the no failure zone, and that the recorded EQGMs seem to have larger damage potential for SDOFS with $\mathrm{T}=1 \mathrm{seco}$

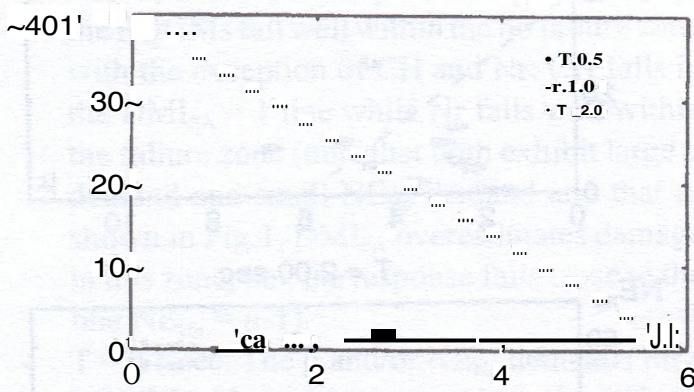

Fig.6 Response of EPP SDOFS with strength according to Costa Rica EQ-RD Code

Target ductility Jor Costa Rica EQGMs. In this section, the effect of duration of motion for the Costa Rica EQGMs is discussed by analyzing their values of $\mu$ TARAs shown in Fig.1, $\mu$ TARs obtained using $\mathrm{DMIpA}=1$ as a failure criteria, and as shown DMIpA tends to underestimate $\mu$ ufor systems subjected to monotonically increasing deformation (compare $\mu \mathrm{uPAand} \mu \mathrm{u}$ in Fig.1). For the values of and $\mu \mathrm{u}$ assumed in this paper, $\mu \mathrm{uPA}=5.4$, which means that according to DMIpA' the maximum ductility a system can undergo under monotonic deformation is 5.4. Fig. 7 shows $\mu$ TARpectra for $\mathrm{C} 1$, $\mathrm{C} 2$ and $\mathrm{C} 3$, and a horizontalline for which $\mu \mathrm{TAR}$ 5.4. For all EQGMs, $\mu$ TARends to 5.4 (monotonic deformation) as $\mathrm{T}$ tends to 0 , and $\mu \mathrm{TARtends}$ to increase monotonicaUy for $\mathrm{T} \sim 3.0$ secoFor sorne $\mathrm{T}$, $\mu$ TARcorresponding to $\mathrm{C} 1$ and $\mathrm{C} 2$ is less than 4 (recall $\mu \mathrm{u}=6$ ), which outlines the relevance of $\mathrm{E}_{\mathrm{H} \mu}$ dissipation for the design ofRC structures for these

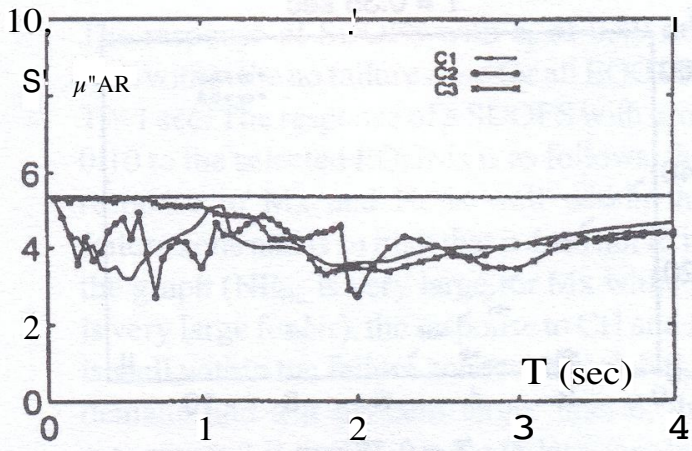

Fig.7 Target ductility for three EQOMs recorded during recent seismic events in Costa Rica

$\mathrm{T}$. Notethat $\mu \mathrm{TARs}$ c1oseto 3.0 for $\mathrm{C} 1$ and $\mathrm{T}$ around $0.5 \mathrm{sec}$, and for $\mathrm{C} 2$ and $\mathrm{T}$ around $0.7 \mathrm{sec}$ and $2 \mathrm{seco}$ ForC3 and $\mathrm{T}<1.0 \mathrm{sec}, \mu \mathrm{TARsaround} 5.4$; nevertheless $\mu$ TARlecreases for larger $\mathrm{T}$ and even gets close to 3.0 forT around $2 \mathrm{sec}$. In fact, small valuesof $\mu \mathrm{TAR}$ can be observed for aUEQGMs and T around 2 seco The results in this section suggest that for sorne $\mathrm{T}$ (around 0.5 and $2 \mathrm{sec}$ ), $\mathrm{E}_{\mathrm{H} \mu}$ dissipation should be of concem in RC structures that develop $\mu$ demands beyond 3 when subjected to $\mathrm{C} 1, \mathrm{C} 2$ and $\mathrm{C} 3$. Fortunately, from the results obtained in the previous section, it can be concluded that the strength of Costa Rica RC ductile frames (Type 1) was enough to control the demand of $\mu$ well below the values of $\mu$ TARhown in Fig.7.

\section{OBSERVA TIONS AND CONCLUSIONS}

In this paper an attempt has been carried out to evaluate the damage potential ofEQGMs recorded during recent seismic events in Costa Rica, and compare this damage potential to that of wellknown EQGMs recorded around the world. For this purpose, the authors have established a reference frame using fundamental concepts of EQ-RD. A few relevant observations follow:

Damage Indexes. Relevant parameters to estimate DMIpAhave been assumed $(13=0.15$ and $\mu \mathrm{u}=6)$ for all SDOFS. Is should be mentioned that considerable analytical and experimental research needs to be carried out not only to determinethe applicability of damage indexes to RC members and buildings, but to evaluate the parameters ( 13 and $\mu \mathrm{u})$ involved in these damage indexes, identifying the depen- 
dency that these parameters have on the structural properties ofreal RC buildings (i.e., detailing, period, structural system, etc.)

Overstrength. Considerable effort needs to be made to estimate the overstrength ofreal buildings according to their structural properties (period, structural system, structural material, design method, etc.).

SDOFS model. In some cases a SDOFS can provide valuable information to assess the behavior of a multi-story building. If upper modes of a regular building are not significant in its total response, an equivalent SDOFS can give a reasonable estimate ofthe global displacement and energy demands of a multi-story building (Qi and Moehle 1991, Zhu et al. 1992).

The damage potential of EQGMs recorded in Costa Rica is considerably smaller than that of other well-known EQGMs. Of the analyzed EQGMs, $\mathrm{Mx}, \mathrm{Nr}$ and $\mathrm{CH}$ seem to have the highest damage potential, although the way and the period range in which they produce significant damage varies considerably. The EQGMs recorded during recent seismic events in Costa Rica (1990 Cóbano EQ, 1990 Alajuela EQ and 1991 Limón EQ) did not produce relevant seismic demands in EPP SDOFS representing ducti le RC structures (Type 1) designed and built in compliance with the current Costa Rica Seismic Codeo Studies to assess the seismic vulnerability of ductil e RC structures located in different cities and towns in Costa Rica need to consider that, in general, the recorded EQGMs have not been a good test to the soundness ofthe behavior of Costa Rica's ductile RC structures. Also, the adequacy of current EQ-RD provisions for the design of ductile RC structures can only be assessed by comparing the magnitude and epicenter location of the recent seismic events in Costa Rica with the magnitude and epicenter location of the seismic events that have been considered for the formulation of such provisions.
It is interesting to note that in spite of the very different characteristics of $\mathrm{C} 1, \mathrm{C} 2$ and $\mathrm{C} 3$, they exhibit important $\mathrm{NE}_{\mathrm{H} \mu}$ demands for $\mathrm{T}$ of 2 sec and constant ductility demand (se e Fig.4). Although not discussed before in this paper, the previous observation seems to be true for several other EQGMs recorded during the Costa Rica seismic events, in which relevant $\mathrm{NE}_{\mathrm{H} \mu}$ demands (for constant ductility) were observed for long $\mathrm{T}$ (around $2 \mathrm{sec}$ ). Although this can beexplained for sorne of tliese EQGMs given that they were recorded at sites with soft soil, it is not as easy to explain for other EQGMs that were recorded in frrm soil $(\mathrm{Cl})$. This issue de serves further research.

\section{ACKNOWLEDGEMENTS}

The work reported in this paper was conducted while both authorswere researchers at the Earthquake Engineering Research Center of the University ofCalifonia at Berkeley. The authors would like to express their sincere gratitude to Prof. V. V. Bertero for his valuable commentaries and the revision ofthis text.The second author would also like to express his gratitude to MEng Jesús Iglesias and to the Universidad Autónoma Metropolitana for the support received through the years.

\section{REFERENCES}

Applied Technology Council. 1978; "Tentative Provisions forthe Development ofSeismic Regulations for Buildings;" ATC 3-06; National BureauofStandards, WashingtonD.C. USA

Araya, R., and G. R. Saragoni. 1984; "Earthquake Accelerogram Destructiveness Potential Factor;" 8th World Conference on Earthquake Engineering, 835-842. San Francisco, California, USA, 21 July 1984. Englewood Cliffs, New Jersey, USA: Prentice-Hall.

Chung, Y.S., Meyer, C. and Shinozuka, M. 1987; "Seismic damage assessment of reinforced concrete members;" Technical Report NCEER-87-0022, National Centerfor Earthquake Engineering Research; Buffalo, New York, USA. 
Cosenza, E., Manfredi, G. and Ramasco, R. 1990; "An evaluation of the use of damage functionals in earthquake resistant design;" Proceedings of the IX European Conference on Earthquake Engineering, Vol. 9, pp. 303-312; Moscow.

Fajfar, P., Vidic, T. and Fischinger, M., 1992; "On energy demand and supply in SDOF systems;" Nonlinear seismic analysis and desiivo of reinforced concrete buildinies. pp. 41-62; Elsevier Applied Science.

Gutiérrez, 1A. et al. 1987; Códi;:o Sísmico de Costa Rica: Editorial Tecnológica de Costa Rica; Cartago, Costa Rica.

Park, Y.J., Ang, A.H. and Wen Y.K. 1985; "Seismic damage analysis ofreinforced concrete buildings;" Journal ofStructural Engineering, ASCE, VoI.111,No.4. NewYork, USA
Qi, X. and Moehle, IP. 1991; "Displacement design approach for reinforced concrete structuressubjected to earthquakes;" Report No. UCBIEERC-91/02; UniversityofCalifornia; Berkeley, California, USA.

Trifunac, M.D. and Brady, A.G.1975; "A study on the duration of strong earthquake ground motion;"Bulletin ofthe Seismological Society of America. Vol. 65, No. 3, pp. 581626, USA.

Uang,c. andBertero, V.V.1988; "Useofenergyas a design criterion in earthquake-resistant design; "Report No. UCBIEERC-88118; University of California; Berkeley, Californi $\sim$ USA.

Zhu, T.J., Tso, W.K. and Heidebrecht, A.C. 1992; "Seismic ellergy demands on reinforced concreteductile moment-resisting frame buildings;" Nonlinear seismic analysis and desi n on reinforced concrete buildin;:s. pp. 95-104; Elsevier Applied Science. 